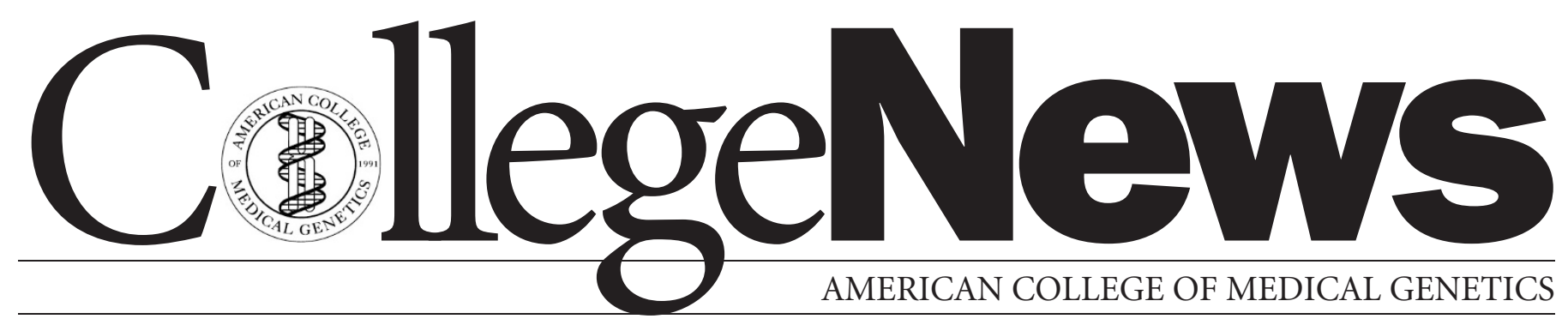

\section{Course Announcement}

\section{ACMG Genetics Review Course \\ June 3-5, 2005 \\ Hyatt Regency O'Hare, Rosemont, Illinois}

This course will provide an overview of clinical genetics with emphasis on current issues. Areas covered will include prenatal genetics, genetic screening, quantitative genetics, genetic syndromes and malformations, biochemical genetics, cancer genetics, basic cytogenetics, chromosomal syndromes, genetics of common disorders and molecular genetics. There will be lectures on the major areas of medical genetics by recognized experts in those fields. The lectures will be reinforced by a syllabus specifically designed to complement the material covered. In addition, participants will take a pre-review examination composed of questions similar to those one might encounter in the Board examinations. These will be graded and the answers to these and other practice questions discussed in workshops that will emphasize problem-solving and faculty/ attendee interaction. CME and CEU credit will be offered for this course.

Detailed announcements will be mailed this autumn to members of ACMG and NSGC, and to all individuals currently enrolled in training programs accredited by the ABMG or the ABGC. Online registration will open early in 2005 via www.acmg.net.

\section{Position Announcement}

\section{Clinical and/or Biochemical Geneticist}

Hayward Genetics Center, Tulane University Health Sciences Center, New Orleans, Louisiana The Hayward Genetics Center seeks a BC/BE Clinical and/or Biochemical Geneticist for an Instructor, Assistant or Associate Professor faculty position at Tulane University Health Sciences Center. The Hayward Genetics Center serves as the referral center for inborn errors of metabolism and also conducts an active clinical and cytogenetics service. Specific responsibilities of this position include directorship of the Clinical Biochemical Genetics Laboratory and participation in teaching and research. A curriculum vitae and three letters of reference should be sent to Jess Thoene, MD, Director Hayward Genetics Center Box SL\#31, Tulane University Health Sciences Center, 1430 Tulane Avenue, New Orleans, LA 70112; telephone (504) 988-5229; FAX (504) 988-1763; e-mail: jthoene@tulane.edu. This search will remain open until a qualified candidate has been identified. Tulane University is an equal opportunity/affirmative action employer, and applications from qualified women and minority group members are especially encouraged. 